UDC $332.145+338.242$

LBC 65.9(Poc...)+65.050

\title{
ESTIMATION OF THE VOLUME OF PRICED SERVICES TO THE POPULATION AS A COMPONENT OF REGIONAL ECONOMY ON THE BASIS OF ECONOMIC AND MATHEMATICAL MODELING
}

\author{
Roman Aleksandrovich Zhukov \\ Tula University (TIEI), Tula, Russian Federation
}

\begin{abstract}
The author estimates the volume of priced services to the population of regions of the Central Federal District as part of the approach to assessing the effectiveness of the control subjects, which contains logically related steps of complex systems analysis and synthesis of solutions aimed at asymmetry alignment and conditions for sustainable development of regional socio-ecological-economic systems (SEES). The research process involves the formation of a generalized performance indicator in the chosen direction out of the plurality of partial indicators, taking into account their mutual influence through the pair of correlation coefficients and is defined as the ratio of the actual value to the standard value. The standard value is calculated by means of modeling the connection of an effective feature with the factors (conditions) of SEES functioning, built with the help of correlation and regression analysis. The author selects the standardized and normalized indicators of the volume of priced services to the population by activity types (13 indicators) as partial indicators of the effectiveness. Condition factors (17 indicators) are combined and related to social and socio-economic groups, each of them being significant, that has a strong link with the productive trait. The connection with environmental factors of condition and impact has not been revealed. The author calculates the coefficient of the harmony characterizing the imbalance of services provided to the population. The synthesis step consists in the search for the desired values of controlled factors in which SEES performance indicators would be compliant with the norm by solving a nonlinear optimization problem with constraints. Within the study for a number of regions the author presents required changes in the selected indicators by solving specific task in a linear form, which can be used as practical recommendations to the authorities of different levels. The data of the Russian state statistics service for 2007-2015 are used as the information base of the present research.
\end{abstract}

Key words: efficiency, socio-ecological-economic systems (SEES), harmony, mathematical model, regression model, social and economic development (SED).

УДК $332.145+338.242$

ББК 65.9(Рос...)+65.050

\section{ОЦЕНКА ОБЬЕМА ПЛАТНЫХ УСЛУГ НАСЕЛЕНИЮ КАК СОСТАВЛЯЮЩЕЙ ЭКОНОМИКИ РЕГИОНОВ НА ОСНОВЕ ЭКОНОМИКО-МАТЕМАТИЧЕСКОГО МОДЕЛИРОВАНИЯ}

\author{
Роман Александрович Жуков \\ Тульский университет (ТИЭИ), г. Тула, Российская Федерация
}


коэффициентов корреляции и определяется как отношение фактического значения к нормативу. Норматив вычисляется по модели связи результативного признака с факторами (условиями) функционирования СЭЭС, построенной с помощью корреляционно-регрессионного анализа. В качестве частных показателей результативности выбраны стандартизованные и нормированные индикаторы объема платных услуг населению по видам деятельности (13 индикаторов). Факторы состояния (17 показателей) объединены и отнесены к социальным и социально-экономическим группам, причем каждый из них существенен, то есть обладает сильной связью с результативным признаком. Связь с экологическими факторами состояния и воздействия не выявлена. Определен коэффициент гармоничности, характеризующий дисбаланс предоставленных услуг населению, рассчитанный по авторской методике. Этап синтеза заключается в поиске требуемых значений управляемых факторов, при котором показатели результативности СЭЭС соответствовали бы нормативу посредством решения нелинейной задачи оптимизации с ограничениями. В рамках исследования для ряда регионов представлены необходимые изменения выбранных индикаторов посредством решения частной задачи в линейном виде, что может быть использовано в качестве практических рекомендаций органам управления различных уровней. В качестве информационной базы были использованы данные Росстата за 2007-2015 годы.

Ключевые слова: эффективность, социо-эколого-экономические системы (СЭЭС), гармоничность, математическая модель, регрессионная модель, социально-экономическое развитие (СЭР).

\section{Введение}

Экономика региона, рассматриваемая как совокупность взаимосвязанных отраслей и секторов, определяет хозяйственную деятельность общества в системе производства, распределения, обмена и потребления. Факторы производства и размещения производительных сил зависят от специфических условий состояния и функционирования конкретной территориально выделенной единицы. Эти условия имеют не только экономическую, но и социальную и экологическую природу. Следовательно, регион необходимо рассматривать как социо-эколого-экономическую систему (СЭЭС). Не случайно современные подходы рассматривают региональную экономику с системных позиций. Н.В. Бозо отмечает, что ее описание связано с использованием методов математического моделирования, которые приобретают дальнейшее развитие, связанное с совершенствованием информационных технологий, позволяющих упростить процедуры анализа данных [3, с. 68].

Наиболее известными и широко используемыми на практике региональными моделями являются модели отдельного региона, включающие модели экономического роста, где в качестве главного фактора выступает внешний спрос (модель экспортной базы); мультипликатор Кейнса (мультипликатор, умноженный на первоначальное изменение инвестиций, дает приращение ВНП); модель межотраслевого баланса (МОБ) [модель (затраты - выпуск)], предложенную В.В. Леонтьевым [9]. В рамках модели Леонтьева могут быть применены нелинейные подходы [8]. Подробный анализ, используемый современными исследователями моделей, в частности, межотраслевых таблиц, представлен в [2].

Подходы к изучению и методы оценки состояния и развития сложных систем (СЭЭС) постепенно претерпевают трансформацию в соответствии с изменяющимися условиями (переход от экономики к социоэкономике), объясняющейся недостаточностью индикаторов, характеризующих только экономическое состояние [1, с. 209]. Традиционный экономический подход «дает возможность глубже раскрыть всю совокупность производственных отношений по поводу производства, распределения, обмена, потребления товаров и услуг. В силу того, что происходит трансформация «рынка производителя» в «рынок потребителя», меняется и отношение к человеку в триаде «природа - хозяйство - население» [1, с. 211]. Следовательно, индикаторы состояния экономики региона априори также должны зависеть от социальных и экологических факторов в сочетании с территориальным размещением производительных сил.

В зависимости от целей и задач исследования, уровня декомпозиции осуществляется и выбор индикаторов оценки, в том числе интегральных показателей, процесс конструирования которых до сих пор остается дискуссионным. При этом необходимо решить проблемы сравнения состояния регионов, которые 
имеют различную отраслевую ориентированность и функционируют в отличных друг от друга условиях. Разделение такой задачи на совокупность частных подзадач анализа элементов СЭЭС и их взаимосвязей в конечном итоге позволит обобщить полученные результаты на всю сложную систему посредством процедуры синтеза, а это является одной из главных целей моделирования состояния и функционирования региона.

Одна из составляющих экономики региона - совокупность платных услуг населению, которые характеризуют полезные результаты производственной деятельности, удовлетворяет определенные потребности населения, что, в свою очередь, определяет их значимость для обеспечения стабильного функционирования СЭЭС. Поэтому их оценка с учетом конкретных условий, факторов влияния является актуальной задачей.

Объектом исследования являются регионы Центрального федерального округа (ЦФО).

Предметом исследования является взаимосвязь объема платных услуг населению по видам деятельности с факторами производства и специфичными территориальными социально-экономическими условиями.

Целью исследования является оценка взаимосвязи экономических показателей результативности состояния социо-эколого-экономических систем с факторами (условиями), оказывающими на них наибольшее влияние, а также их сравнение для отдельных регионов ЦФО.

В рамках исследования решаются следующие задачи:

- выделить факторы, характеризующие объем платных услуг для СЭЭС;

- построить модели связи показателей результативности с факторными признаками на основании подхода к оценке эффективности деятельности субъектов управления с использованием авторского программного комплекса;

- проанализировать состояние регионов ЦФО в части изучения объема платных услуг населению;

- определить направления оптимизации управляемых факторов.

Гипотеза исследования предполагает наличие существенных связей между объемом платных услуг населению и факторами состояния и воздействия, имеющих социальную, экологическую и экономическую природу.

Практическая значимость исследования определяется возможностью использования полученных результатов региональными органами управления в части разработки мероприятий, направленных на удовлетворение определенных потребностей населения.

\section{Теоретические аспекты оценки объема платных услуг населению}

Для оценки объема платных услуг населению можно воспользоваться показателями, ежегодно предоставляемыми Федеральной службой государственной статистики РФ, в том числе по видам деятельности: бытовые услуги, транспортные услуги, услуги связи, коммунальные и жилищные услуги, услуги в системе образования, услуги правового характера, ветеринарные услуги, медицинские услуги, услуги физической культуры и спорта, туристские услуги, услуги учреждений культуры, услуги гостиниц и аналогичных средств размещения, санаторно-оздоровительные услуги. Для учета влияния уровня цен необходимо скорректировать соответствующие показатели по паритету покупательной способности (ППС) в долларах США.

Для отбора факторных признаков в рамках исследования предложено проводить его по критерию существенности в аналитической схеме «результат - состояние - воздействие».

Построение показателей результативности осуществляется на основании подхода, представленного в [7, с. 272], и алгоритмом их вычисления [6, с. 271], апробированном на примере оценки состояния атмосферного воздуха в регионах ЦФО [5].

Показатель результативности определяется по формуле:

$$
\xi_{k}=\frac{\xi_{k, \text { факт }}}{\xi_{k, \text { расч }}}
$$

где $\xi_{k}-$ значение обобщающего показателя; $\xi_{k, \text { факт }}-$ фактическое и $\xi_{k \text { расч }}-$ «нормативное» (расчетное) значения обобщающего показателя.

Фактическое и нормативное значения определяются по формулам: 


$$
\begin{gathered}
\xi_{k, \text { факт }}=\left[\sum_{i=1}^{m} \sum_{j=1}^{m} r_{i j, \text { факт }} \cdot y_{i, \text { факт }} \cdot y_{j, \text { факт }}\right]^{1 / 2}, \\
\xi_{k, \text { расч }}=\left[\sum_{i=1}^{m} \sum_{j=1}^{m} \sum_{p=1}^{n} \sum_{q=1}^{n} r_{i j \text { расч }} \cdot C_{i p} \cdot C_{j p} \cdot x_{k p} \cdot x_{k q}\right]^{1 / 2},
\end{gathered}
$$

где $m$ - число результативных признаков; $n$ - число факторных признаков (условий); $i$ - индекс $i$-го результативного признака; $j$ - индекс $j$-го результативного признака; $p$ - индекс $p$-го факторного признака; $q$ - индекс $q$-го факторного признака; $k-$ индекс рассматриваемой единицы совокупности; $y_{i, \text { факт }} y_{j, \text { факт }}-$ фактические значения результативных признаков; $r_{i j \text { факт }}, r_{i j \text { расч }}-$ парные коэффициенты корреляции между $i$-м и $j$-м результативными признаками (фактическими и расчетными); $C_{i p}$ - весовой коэффициент между $i$-м результативным и $p$-м факторным признаками; $C_{j q}-$ весовой коэффициент между $j$-м результативным признаком и $q$-м фактором; $x_{k p}$ - фактическое значение стандартизованного $p$-го факторного признака для $k$-й единицы совокупности; $x_{k q}$ - фактическое значение стандартизованного $q$-го факторного признака для $k$-й единицы совокупности. Коэффициенты $C_{i p}, C_{j q}$ являются параметрами регрессий, представленных в стандартизованном виде, и определяются с помощью пошагового метода наименьших квадратов. Отметим, что все результативные признаки заданы в стандартизованном виде и нормированы, то есть приведены к шкале от 0 до 1, что обеспечивает их сравнимость и возможность дальнейшего использования без учета их физического и экономического смысла.

Если показатель меньше единицы (не достигает норматива), то состояние СЭЭС по данному индикатору неблагоприятно.

При этом каждый из результативных признаков, входящих в соотношение (3), можно рассматривать отдельно, в виде линейной модели:

$$
y_{k, \mathrm{pac} \varphi}=\sum_{i=1}^{n} C_{i k} \cdot x_{i k},
$$

используя ее в формуле (1) при оценке соответствия частных показателей нормативному значению. При этом оказывается возможность оценить асимметрию объема платных услуг для каждой оцениваемой территории, что характеризует гармоничность состояния системы по выделенным параметрам. Под гармоничностью понимается равномерность исследуемых показателей, которые должны быть близки к единице, то есть соответствовать нормативу.

Коэффициент гармоничности оценивается с помощью соотношения:

$$
K_{k}=1-\frac{\sigma\left(y_{i, k}\right)}{M\left(y_{i, k}\right)},
$$

где

$$
M\left(y_{i, k}\right)=\frac{1}{n} \sum_{i=1}^{n} y_{i, k}-
$$

математическое ожидание,

$$
\sigma\left(y_{i, k}\right)=\sqrt{\frac{1}{n} \sum_{i=1}^{n}\left(\left(y_{i, k}-M\left(y_{i, k}\right)\right)^{2}\right.} .
$$

Среднеквадратическое отклонение. Чем ближе коэффициент гармоничности к единице, тем равномернее предоставление платных услуг населению по видам деятельности.

\section{Результаты исследования}

Для выбранных показателей результативности были построены модели в стандартизованном виде с использованием пошагового метода наименьших квадратов и статистических данных за 2007-2015 годы [10]. Модели используются для вычисления норматива изучаемой единицы совокупности, посредством подстановки в нее фактических значений факторов состояния и воздействия. На первом этапе в моделях анализировались более 30 факторов, имеющих социальный, экономический и экологический характер (исключение проводилось по оценке значимости коэффициентов и мультиколлинеарности, а также качественного анализа). Расчеты проводились с помощью авторской экспертной системы принятия решений (бета-версия) [4, с. 555].

$$
\begin{gathered}
y_{1}=0,979 \cdot x_{1}, \\
y_{2}=0,700 \cdot x_{2.2}+0,197 \cdot x_{3}+0,107 \cdot x_{4}, \\
y_{3}=0,817 \cdot x_{1} \\
y_{5}=0,369 \cdot x_{1}+0,395 \cdot x_{2.5}+0,253 \cdot x_{6.5}, \\
y_{6}=0,785 \cdot x_{1}, \\
y_{7}=0,915 \cdot x_{1}, \\
y_{8}=0,943 \cdot x_{2.8}+0,057 \cdot x_{7},
\end{gathered}
$$




$$
\begin{gathered}
y_{9}=0,515 \cdot x_{8.1}+0,138 \cdot x_{8.2}+0,323 \cdot x_{8.3},(16) \\
y_{10}=0,488 \cdot x_{9}+0,496 \cdot x_{10}, \\
y_{11}=0,921 \cdot x_{1}, \\
y_{12}=0,742 \cdot x_{2.12}+0,252 \cdot x_{6.12}, \\
y_{13}=0,955 \cdot x_{1} .
\end{gathered}
$$

Здесь $y_{1}$ - бытовые услуги (здесь и далее все показатели, которые представляются в стоимостном выражении, скорректированы по паритету покупательной способности в долларах США); $y_{2}$ - транспортные услуги; $y_{3}-$ услуги связи; $y_{4}-$ коммунальные и жилищные услуги (объединены вследствие зависимости от одинаковых факторных признаков); $y_{5}-$ услуги в системе образования; $y_{6}-$ услуги правового характера; $y_{7}$ - ветеринарные услуги; $y_{8}-$ медицинские услуги; $y_{9}$ - услуги физической культуры и спорта; $y_{10}$ - туристские услуги; $y_{11}$ - услуги учреждений культуры; $y_{12}-$ услуги гостиниц и аналогичных средств размещения; $y_{13}$ - санаторно-оздоровительные услуги; $x_{1}-$ среднегодовая численi î ñö í àñåäåí èÿ; $x_{2 . i}$ - среднегодовая численность занятых по видам экономической деятельности $\left(x_{2.2}\right.$ - транспорт, $x_{2.4}$ - предоставление прочих коммунальных, социальных и персональных услуг, $x_{2.5}$ - образование, $x_{2.8}$ здравоохранение, $x_{2.12}$ - гостиницы и рестораны); $x_{3}$ - пассажирооборот автобусов общего пользования; $x_{4}-$ отправление пассажиров железнодорожным транспортом общего пользования; $x_{5.4}$ - расходы консолидированного бюджета на ЖКХ; $x_{6 . i}-$ инвестиции в основной капитал по виду деятельности $\left(x_{6.5}-\right.$ образо- вание, $x_{6.12}$ - гостиницы и рестораны); $x_{7}$ - заболеваемость на 1000 человек населения (зарегистрировано заболеваний у пациентов с диагнозом, установленным впервые в жизни); $x_{8 i}$ - число спортивных сооружений $\left(x_{8.1}-\right.$ стадионы с трибунами на 1500 мест и более, $x_{8.2}$ - спортивные залы, $x_{8.3}$ - плавательные бассейны); $x_{9}$ - число туристских фирм; $x_{10}$ численность российских туристов, отправленных туристскими фирмами в зарубежные туры. Все стандартизованные коэффициенты в построенных моделях оказались значимыми по критерию Стьюдента для уровня значимости 0,05 и соответствующих степеней свободы.

Визуализация данных (рис. 1) демонстрирует несколько групп факторов, которые можно отнести к социальным $\left(x_{1}, x_{7}, x_{8 . i}, x_{9}\right.$, $\left.x_{10}\right)$ и социально-экономическим $\left(x_{2 . i}, x_{3}, x_{4}\right)$ факторам состояния.

Например, занятость является экономической категорией и социальной. Факторы воздействия $\left(x_{5.4}, x_{6 . .}\right)$ относятся к экономической группе, хотя направлены на решение социальных и экономических задач. Существенных экологических факторов состояния и воздействия в процессе построения моделей не выявлено, также не выявлено существенное влияние реальных доходов населения на объем платных услуг всех категорий.

Показатели качества моделей представлены в таблице 1.

В таблице 1 обозначено: $R_{i}^{2}$ - коэффициент детерминации; $R_{i}$ - коэффициент множественной корреляции; $\sigma$ - стандартная ошибка (среднеквадратическое отклонение остат-

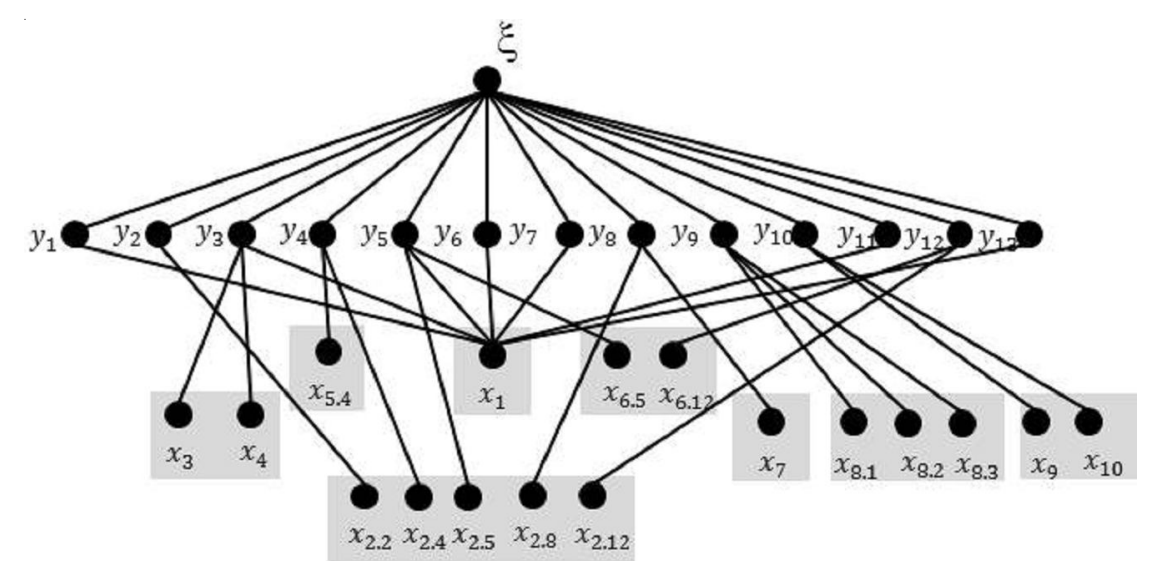

Рис. 1. Схема связей между результативными и факторными признаками

Примечание. Составлено автором. 
P.А. Жуков. Оценка объема платных услуг населению как составляющей экономики регионов

ков); $F_{\text {расч }}$ - расчетное значение критерия Фишера; $v$ - число степеней свободы. Критическое значение для моделей по критерию Фишера $F_{\text {кр }}=3,904$ для $5 \%$ уровня значимости.

Для преобразования переменных к стандартизованному виду использовались соотношения:

$$
x_{i}=\frac{x_{i}^{\prime}-\bar{x}_{i}^{\prime}}{\sigma_{x_{i}^{\prime}}}, y=\frac{y_{1}^{\prime}-\bar{y}^{\prime}}{\sigma_{y_{1}^{\prime}}},
$$

где «'»- абсолютное значение параметра; $\sigma$ - среднеквадратическое отклонение; $\bar{x}, \bar{y}$ - средние значения факторных и результативных признаков.

Приведенные признаки были вычислены по формуле:

$$
Y_{i}=\frac{Y_{i}-Y_{\min }}{Y_{\max }-Y_{\min }} .
$$

Обобщенный показатель результативности рассчитывался по формулам (1)-(3) (табл. 2).

Из таблицы 2 можно сделать вывод, что наилучшая результативность в 2015 г. наблюдается в Костромской области, а наихудшая в Смоленской области. При этом для всех регионов соответствующий показатель увеличивался до 2014 г., а в 2015 г. немного сократился, за исключением Тверской и Тульской областей, где сохранилась положительная динамика (см. рис. 2).

На основании такого представления можно сформировать рейтинг регионов по объему платных услуг населению. При этом можно оценить уровень как не соответствующий (значение меньше единицы) или соответствующий (значение больше единицы) нормативу, что требует более детального изучения отдельных частных индикаторов для Московской, Рязанской, Смоленской, Тульской и Ярославской областей (см. табл. 3).

В таблице 3 обозначено: 10 - Московская область; 12 - Рязанская область; 16 Тульская область; 17 - Ярославская область.

Если показатель результативности меньше единицы, то это означает, что при заданных конкретных условиях (факторных признаков) ожидаемый объем платных услуг не достигается. В соответствии с построенными моделями показатели $y_{1}, y_{3}, y_{5}, y_{6}, y_{7}, y_{11}, y_{13}$ зависят от среднегодовой численности населения. Следовательно, имеет место несоот-

\begin{tabular}{|c|c|c|c|c|c|}
\hline Модель/Показатель & $\mathrm{R}_{\mathrm{i}}^{2}$ & $\mathrm{R}_{\mathrm{i}}$ & $\sigma$ & $\mathrm{F}_{\text {расч }}$ & $v$ \\
\hline Бытовые услуги $\left(\mathrm{y}_{1}\right)$ & 0,958 & 0,979 & 121,200 & 3455,2 & 151 \\
\hline Транспортные услуги $\left(\mathrm{y}_{2}\right)$ & 0,953 & 0,976 & 117,350 & 1002,1 & 149 \\
\hline У слуги связи $\left(\mathrm{y}_{3}\right)$ & 0,668 & 0,817 & 122,990 & 303,6 & 151 \\
\hline $\begin{array}{l}\text { Коммунальные и жилищные услуги } \\
\left(\mathrm{y}_{4}\right)\end{array}$ & 0,978 & 0,989 & 257,330 & 3394,5 & 116 \\
\hline У слуги в системе образования ( y $\left._{5}\right)$ & 0,958 & 0,979 & 28,443 & 1392,1 & 149 \\
\hline У слуги правового характера $\left(\mathrm{y}_{6}\right)$ & 0,615 & 0,784 & 17,171 & 241,7 & 151 \\
\hline Ветеринарные услуги $\left(\mathrm{y}_{7}\right)$ & 0,838 & 0,915 & 3,674 & 780,3 & 151 \\
\hline Медицинские услуги ( у $\left._{8}\right)$ & 0,796 & 0,892 & 66,710 & 359,7 & 150 \\
\hline $\begin{array}{l}\text { Услуги физической культуры и } \\
\text { спорта }\left(\mathrm{y}_{9}\right)\end{array}$ & 0,859 & 0,927 & 12,688 & 302,5 & 132 \\
\hline Туристские услуги $\left(\mathrm{y}_{10}\right)$ & 0,931 & 0,965 & 16,130 & 1017,7 & 99 \\
\hline У слуги учреждений культуры ( 甲 $\left._{11}\right)$ & 0,847 & 0,921 & 15,691 & 839,1 & 151 \\
\hline $\begin{array}{l}\text { Услуги гостиниц и аналогичных } \\
\text { средств размещения }\left(\mathrm{y}_{12}\right)\end{array}$ & 0,952 & 0,976 & 15,915 & 1491,0 & 150 \\
\hline $\begin{array}{l}\text { Санаторно-оздоровительные услуги } \\
\left(\mathrm{y}_{13}\right)\end{array}$ & 0,913 & 0,955 & 30,197 & 1581,9 & 100 \\
\hline
\end{tabular}

Показатели качества моделей

Примечание. Составлено автором. 
Динамика обобщенного показателя результативности для регионов ЦФО в 2011-2015 гг.

\begin{tabular}{|l|c|c|c|c|c|}
\hline \multicolumn{1}{|c|}{ Субъект/Показа тель } & 2011 & 2012 & 2013 & 2014 & 2015 \\
\hline Белгородская область & 0,997 & 1,097 & 1,239 & 1,329 & 1,282 \\
\hline Брянская область & 1,077 & 1,117 & 1,178 & 1,295 & 1,233 \\
\hline Владимирская область & 0,933 & 1,069 & 1,208 & 1,269 & 1,18 \\
\hline Воронежская область & 0,913 & 0,974 & 1,03 & 1,125 & 1,121 \\
\hline Ивановская область & 0,97 & 0,989 & 0,998 & 1,146 & 1,13 \\
\hline Калужская область & 1,249 & 1,364 & 1,422 & 1,512 & 1,337 \\
\hline Костромская область & 1,202 & 1,54 & 1,773 & 2,094 & 1,926 \\
\hline Курская область & 1,036 & 1,092 & 1,228 & 1,365 & 1,327 \\
\hline Липецкая область & 1,045 & 1,147 & 1,289 & 1,456 & 1,416 \\
\hline Московская область & 0,863 & 0,859 & 1,063 & 1,06 & 0,995 \\
\hline Орловская область & 0,999 & 1,085 & 1,256 & 1,389 & 1,319 \\
\hline Рязанская область & 0,994 & 0,989 & 0,958 & 0,97 & 0,973 \\
\hline Смоленская область & 0,726 & 0,737 & 0,758 & 0,874 & 0,776 \\
\hline Тамбовская область & 1,108 & 1,079 & 1,118 & 1,248 & 1,228 \\
\hline Тверская область & 0,944 & 0,978 & 0,994 & 0,953 & 1,06 \\
\hline Тульская область & 0,837 & 0,852 & 0,855 & 0,898 & 0,908 \\
\hline Ярославская область & 0,855 & 0,858 & 0,929 & 0,962 & 0,94 \\
\hline
\end{tabular}

Примечание. Составлено автором.

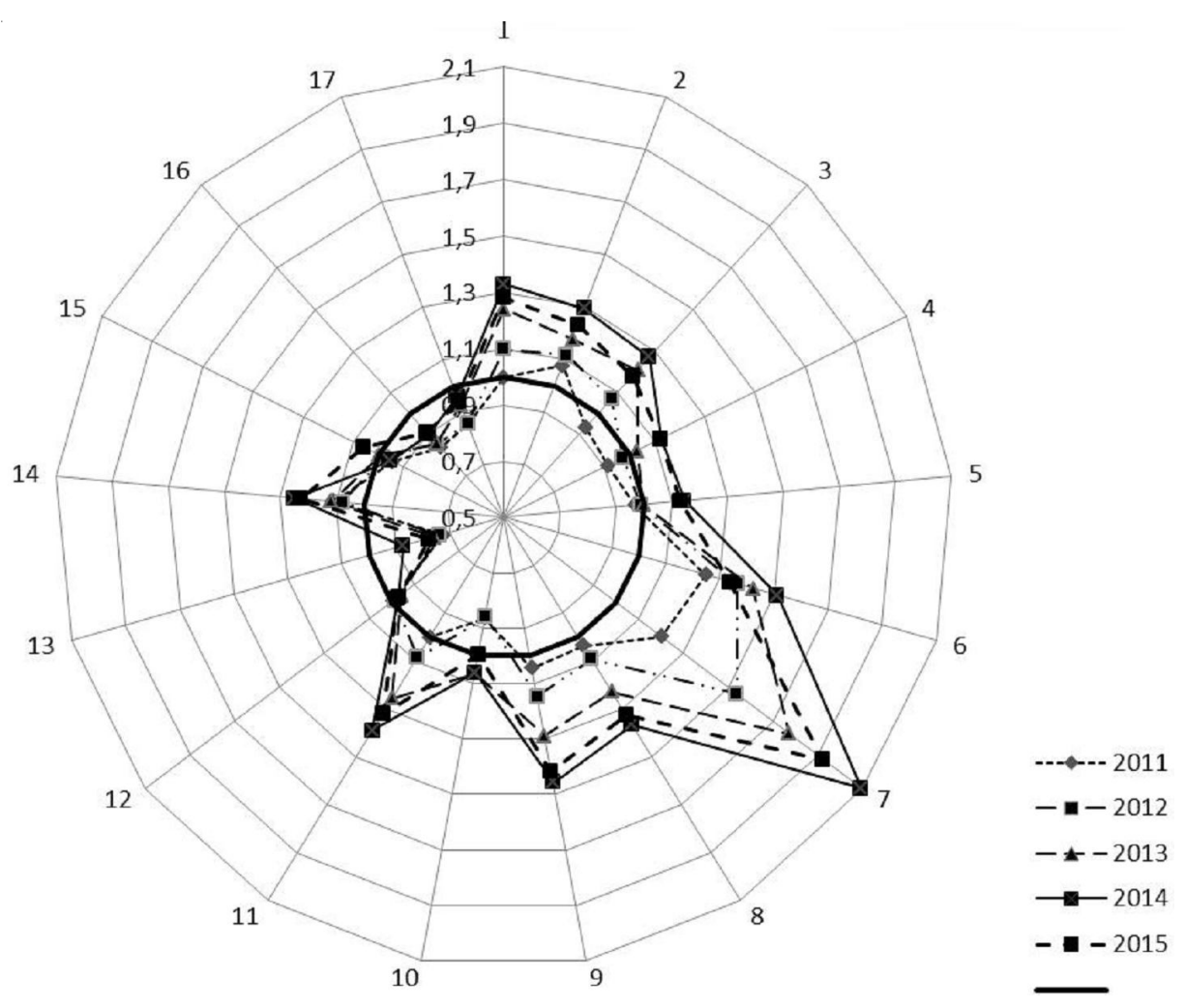

Рис. 2. Динамика обобщенного показателя результативности для регионов ЦФО:

1 - Белгородская; 2 - Брянская; 3 - Владимирская; 4 - Воронежская; 5 - Ивановская; 6 - Калужская;

7 - Костромская; 8 - Курская; 9 - Липецкая, 10 - Московская; 11 - Орловская; 12 - Рязанская; 13 - Смоленская; 14 - Тамбовская; 15 - Тверская; 16 - Тульская; 17 - Ярославская области

Примечание. Составлено автором. 
Р.А. Жуков. Оценка объема платных услуг населению как составляющей экономики регионов

Показатели результативности в 2015 г.

\begin{tabular}{|c|c|c|c|c|c|}
\hline Показатель/№ региона & 10 & 12 & 13 & 16 & 17 \\
\hline Бытовые услуги ( $\left.\mathrm{y}_{1}\right)$ & 1,02 & 0,656 & 0,658 & 0,755 & 0,575 \\
\hline Транспортные услуги ( y $\left._{2}\right)$ & 0,805 & 0,217 & 0,248 & 1,024 & 0,539 \\
\hline Услуги связи $\left(\mathrm{y}_{3}\right)$ & 1,11 & 0,987 & 0,578 & 1,209 & 0,938 \\
\hline Коммунальные и жилищные услуги $\left(\mathrm{y}_{4}\right)$ & 1,013 & 1,675 & 1,392 & 0,613 & 1,094 \\
\hline Услуги в системе образования $\left(\mathrm{y}_{5}\right)$ & 0,99 & 1,047 & 1,152 & 0,956 & 1,053 \\
\hline Услуги правового характера $\left(\mathrm{y}_{6}\right)$ & 1,083 & 0,721 & 1,616 & 1,01 & 0,522 \\
\hline Ветеринарные услуги $\left(\mathrm{y}_{7}\right)$ & 1,116 & 0,119 & 0,403 & 0,509 & 0,648 \\
\hline Медицинские услуги ( $\left.\mathrm{y}_{8}\right)$ & 1,431 & 1,73 & 1,433 & 1,677 & 0,914 \\
\hline Услуги физической культуры и спорта ( 甲 $\left._{9}\right)$ & 1,179 & 1,868 & 0,489 & 1,057 & 4,316 \\
\hline Туристские услуги ( $\left.\mathrm{y}_{10}\right)$ & 0,927 & 0,885 & 0,188 & 0,916 & 0,505 \\
\hline Услуги учреждений культуры ( 甲 $_{11}$ ) & 1,235 & 1,489 & 0,823 & 1,071 & 1,856 \\
\hline $\begin{array}{l}\text { Услуги гостиниц и аналогичных средств } \\
\text { размещения }\left(\mathrm{y}_{12}\right)\end{array}$ & 0,841 & 2,071 & 1,182 & 15,915 & 1,165 \\
\hline Санаторно-оздоровительные услуги ( $\left.\mathrm{y}_{13}\right)$ & 0,717 & 2,071 & 1,179 & 30,197 & 1,185 \\
\hline
\end{tabular}

Примечание. Составлено автором.

ветствие спроса и предложения на данные виды услуг вследствие их некачественного характера и (или) необоснованного уровня цен. Объем транспортных услуг определяется занятостью населения в данной сфере, пассажирооборотом автобусов и железнодорожного транспорта общего пользования. Одними из причин отклонения от норматива соответствующего индикатора могут являться низкие тарифы на транспортные услуги, которые определяют органы местного самоуправления. Индикатор объема коммунальных и жилищных услуг не соответствует нормативу только для Тульской области и определяется несоответствием тарифов, излишним количеством занятых в данной сфере, а также нерациональным использованием статьи консолидированного бюджета, направляемого на жилищно-коммунальное хозяйство. Ежегодное увеличение тарифов не изменяет негативную динамику $(0,613$ в 2015 г. против 0,654 в 2014 г.), что объясняется увеличением должников и не решает проблему в целом. Для Ярославской области в 2015 г. наблюдалось уменьшение индикатора объема медицинских услуг (0,914 в 2015 г. против 1,02 в 2014 г.), связанного с уровнем занятости и заболеваемости населения. В Смоленской области в сфере физической культуры и спорта можно судить о недостаточном использовании имеющихся спортивных сооружений. Наихудшая ситуация складывается в сфере предоставления туристических услуг населению, определяемая общеэкономическими тенденциями, и, в соответствии с моделью, снижением общего спроса, а также приобретением более дешевых туров. В Московской области низкое значение индикатора предоставления гостиничных услуг свидетельствует о проблемах в сфере занятости и инвестирования. Для более детального изучения причин, обусловливающих недостаточный уровень показателей результативности, необходимо рассматривать регион как совокупность муниципальных образований (MO) и проводить анализ факторов состояния и воздействия уже в таком разрезе. Это позволит конкретизировать подсистемы (условия их функционирования), формирующие общую картину для региона с низкими значениями индикаторов.

Для количественной оценки возможных мероприятий необходимо провести процедуру оптимизации в соответствии с авторским алгоритмом синтеза управленческих решений $[7$, c. 273]:

$\left[\sum_{i=1}^{m} \sum_{j=1}^{m} \sum_{p=1}^{n} \sum_{q=1}^{n} r_{i j} \cdot C_{i p} \cdot C_{j q} \cdot \frac{x_{k q}}{K_{k p}} \cdot \frac{x_{k q}}{K_{k q}}\right]^{1 / 2}-\xi_{k, \text { факт }} \rightarrow \min$, 
для $\xi_{i k}<1$ и акселераторов $K_{k p}$, имеющих смысл необходимых изменений факторных признаков с целью достижения норматива (рациональное управленческое решение). В простейшем случае функция оптимизируется по одному из параметров, входящих в модель при фиксированных значениях других параметров (табл. 4).

Данные таблицы 4 можно интерпретировать как: на сколько \% в среднем наблюдается перерасход («-») или излишек («+») факторного признака, в связи с чем норматив не достигается, 0 обозначает, что оптимизация для данного субъекта не требуется, н/p - нереализуемо при оптимизации только одного фактора (>100 \%).

Наиболее оптимальное решение предполагает изменение факторов на 10-15\%.
Анализ коэффициента гармоничности показал сильную дифференциацию в предоставляемых услугах населению регионов ЦФО (см. рис. 3).

Наилучшая гармоничность наблюдается в Московской области, то есть равномерность объема предоставляемых услуг по выбранным сферам деятельности с учетом конкретных условий функционирования СЭЭС.

Таким образом, в рамках проведенного исследования получены следующие результаты.

Для оценки объема платных услуг населению применен авторский подход, позволяющий сформировать собственный норматив для выбранного региона с учетом конкретных условий функционирования и рассматриваемый как социо-эколого-экономическая система. Изучены соответствующие индикаторы на

Оптимизация показателей результативности по фактору

Таблица 4

\begin{tabular}{|c|c|c|c|c|c|}
\hline Показатель/oㅡегиона & $\mathbf{1 0}$ & $\mathbf{1 2}$ & $\mathbf{1 3}$ & $\mathbf{1 6}$ & $\mathbf{1 7}$ \\
\hline $\mathrm{y}_{1} / \mathrm{x}_{1}$ & 0 & $-14,89$ & $-11,27$ & $-14,21$ & $-21,13$ \\
\hline $\mathrm{y}_{2} / \mathrm{x}_{2.2}$ & $-25,74$ & $-53,54$ & $-53,30$ & 0 & $-41,68$ \\
\hline $\mathrm{y}_{2} / \mathrm{x}_{3}$ & $\mathrm{H} / \mathrm{p}$ & $\mathrm{H} / \mathrm{p}$ & $\mathrm{H} / \mathrm{p}$ & 0 & $\mathrm{H} / \mathrm{p}$ \\
\hline $\mathrm{y}_{2} / \mathrm{x}_{4}$ & $\mathrm{H} / \mathrm{p}$ & $\mathrm{H} / \mathrm{p}$ & $\mathrm{H} / \mathrm{p}$ & 0 & $\mathrm{H} / \mathrm{p}$ \\
\hline $\mathrm{y}_{3} / \mathrm{x}_{1}$ & 0 & $-1,60$ & $-50,00$ & 0 & $-7,37$ \\
\hline $\mathrm{y}_{4} / \mathrm{x}_{2.4}$ & 0 & 0 & 0 & $-30,99$ & 0 \\
\hline $\mathrm{y}_{4} / \mathrm{x}_{5.4}$ & 0 & 0 & 0 & $\mathrm{H} / \mathrm{p}$ & 0 \\
\hline $\mathrm{y}_{5} / \mathrm{x}_{1}$ & 0 & 0 & 0 & $-8,07$ & 0 \\
\hline $\mathrm{y}_{5} / \mathrm{x}_{25}$ & 0 & 0 & 0 & $-5,56$ & 0 \\
\hline $\mathrm{y}_{5} / \mathrm{x}_{65}$ & 0 & 0 & 0 & $-29,87$ & 0 \\
\hline $\mathrm{y}_{6} / \mathrm{x}_{1}$ & 0 & $-25,76$ & 0 & 0 & $-45,97$ \\
\hline $\mathrm{y}_{6} / \mathrm{x}_{1}$ & 0 & $-56,50$ & $-33,54$ & $-37,05$ & $-24,31$ \\
\hline $\mathrm{y}_{8} / \mathrm{x}_{2.8}$ & 0 & 0 & 0 & 0 & $-5,15$ \\
\hline $\mathrm{y}_{8} / \mathrm{x}_{7}$ & 0 & 0 & 0 & 0 & $-13,74$ \\
\hline $\mathrm{y}_{9} / \mathrm{x}_{8.1}$ & 0 & 0 & $-84,51$ & 0 & 0 \\
\hline $\mathrm{y}_{8} / \mathrm{x}_{7}$ & 0 & 0 & $\mathrm{H} / \mathrm{p}$ & 0 & 0 \\
\hline $\mathrm{y}_{8} / \mathrm{x}_{7}$ & 0 & 0 & $\mathrm{H} / \mathrm{p}$ & 0 & 0 \\
\hline $\mathrm{y}_{10} / \mathrm{x}_{9}$ & $-14,22$ & $-10,73$ & $-63,02$ & $-7,58$ & $-73,94$ \\
\hline $\mathrm{y}_{10} / \mathrm{x}_{10}$ & $-14,56$ & $-17,43$ & $\mathrm{H} / \mathrm{p}$ & $-35,43$ & $-71,89$ \\
\hline $\mathrm{y}_{11} / \mathrm{x}_{1}$ & 0 & 0 & $-6,18$ & 0 & 0 \\
\hline $\mathrm{y}_{12} / \mathrm{x}_{2.12}$ & $-16,31$ & 0 & 0 & 0 & 0 \\
\hline $\mathrm{y}_{12} / \mathrm{x}_{6.12}$ & $-62,23$ & 0 & 0 & 0 & 0 \\
\hline $\mathrm{y}_{13} / \mathrm{x}_{1}$ & $-26,98$ & 0 & 0 & 0 & 0 \\
\hline
\end{tabular}

Примечание. Составлено автором. 


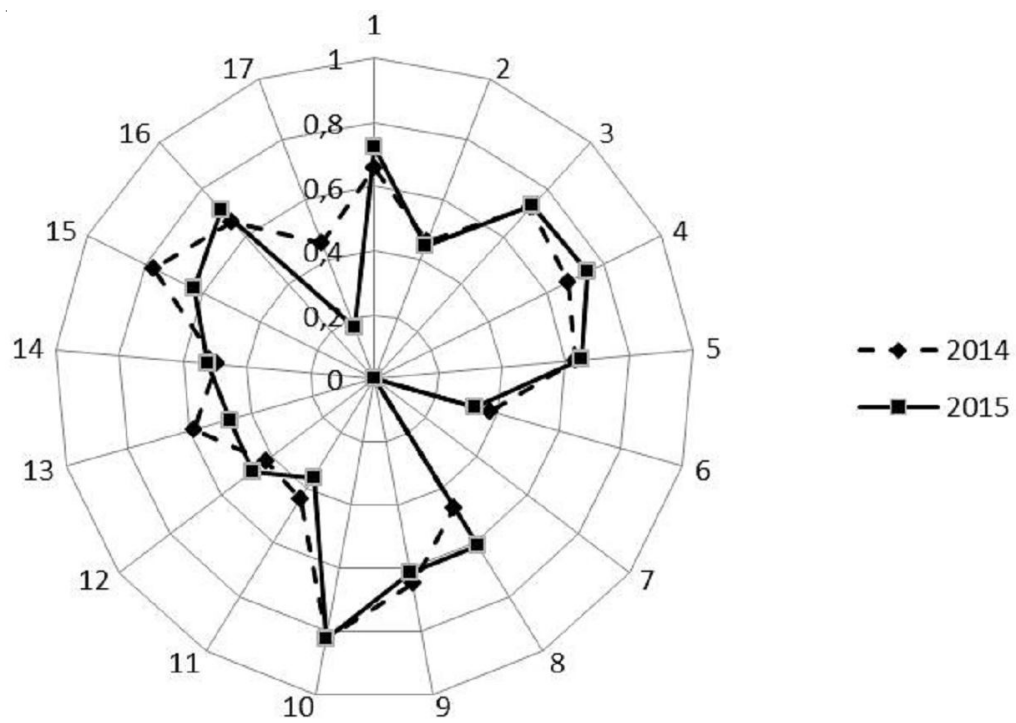

Рис. 3. Коэффициент гармоничности для регионов ЦФО в 2014-2015 гг.:

1 - Белгородская; 2 - Брянская; 3 - Владимирская; 4 - Воронежская; 5 - Ивановская; 6 - Калужская; 7 - Костромская; 8 - Курская; 9 - Липецкая, 10 - Московская; 11 - Орловская; 12 - Рязанская; 13 - Смоленская; 14 - Тамбовская; 15 - Тверская; 16 - Тульская; 17 - Ярославская области

Примечание. Составлено автором.

основании построенных моделей связи. Оценена гармоничность предоставления платных услуг населению в регионах ЦФО. В рамках исследования на основании процедуры оптимизации определены и количественно выражены практические рекомендации субъектам экономики в целях совершенствования своей деятельности. В последующих исследованиях предполагается объединить экономическую, социальную и экологическую составляющие, сформировав тем самым комплексную оценку состояния и функционирования региона, рассматриваемого как СЭЭС.

\section{СПИСОК ЛИТЕРАТУРЫ}

1. Анимица, Е. Г. Трансформация научных подходов и методов изучения региональной социоэкономики / Е. Г. Анимица, Т. А. Балина, М. Д. Шарыгин // Вестник Пермского национального исследовательского политехнического университета. Социально-экономические науки. - 2016. - № 4. C. 209-218.

2. Баранов, А. О. Построение и использование региональных межотраслевых моделей для анализа и прогнозирования развития экономики регионов / А. О. Баранов, З. Б. Дондоков, Ю. М. Слепенкова // Идеи и идеалы. - 2016. - Т. 2, № 4 (30). -С. 66-85.

3. Бозо, Н. В. Региональная экономика / Н. В. Бо3о. - Новосибирск : Изд-во НГТУ, 2012. - 196 с.
4. Жуков, Р. А. Внедрение программных экономико-математических комплексов в практику деятельности органов государственного управления / Р. А. Жуков // Фундаментальные исследования. 2015. - № 9-3. - С. 555-559.

5. Жуков, Р. А. Оценка состояния атмосферного воздуха в регионах ЦФО в рамках фундаментального подхода к оценке эффективности деятельности субъектов управления социо-эколого-экономическими системами / Р. А. Жуков // Вестник Волгоградского государственного университета. Серия 3, Экономика. Экология. - 2016. - № 3 (36). C. $177-184$.

6. Жуков, Р. А. Применение инновационного подхода к прогнозированию показателей социально-экономического развития в МО Узловский район Тульской области / Р. А. Жуков // Вестник Тульского филиала Финуниверситета. - 2014. - № 1. C. $271-273$.

7. Жуков, Р. А. Применение фундаментального подхода к управлению социально-экономическим развитием территорий / Р. А. Жуков // Научное обозрение. - 2014. - № 4. - С. 272-274.

8. Жуланов, Е. Е. Экономико-математическое моделирование развития воспроизводственного контура региональной социально-экономической системы / Е. Е. Жуланов // Экономический анализ: теория и практика. - 2016. - № 6 (453). - С. 172-187.

9. Леонтьев, В. В. Баланс народного хозяйства СССР. Методологический разбор работы ЦСУ / В. В. Леонтьев // Плановое хозяйство. - М. : Госплан СССР, 1925. - № 12. - С. 254-258. 
10. Федеральная служба государственной статистики. - Электрон. текстовые дан. - Режим доступа: http://www.gks.ru (дата обращения: 20.04.2017). - Загл. с экрана.

\section{REFERENCES}

1. Animitsa E.G., Balina T.A., Sharygin M.D. Transformatsiya nauchnykh podkhodov i metodov izucheniya regionalnoy sotsioekonomiki [Transformation of Scientific Approaches and Methods of Studying Regional Socio-Economics]. Vestnik Permskogo natsionalnogo issledovatelskogo politekhnicheskogo universiteta. Sotsial'noekonomicheskie nauki, 2016, no. 4, pp. 209-218.

2. Baranov A.O., Dondokov Z.B., Slepenkova Yu.M. Postroenie i ispolzovanie regionalnykh mezhotraslevykh modeley dlya analiza i prognozirovaniya razvitiya ekonomiki regionov [Construction and Use of Regional Interindustry Models for Analyzing and Forecasting Economic Development of Regions]. Idei i idealy, 2016, vol. 2, no. 4 (30), pp. 66-85.

3. Bozo N.V. Regionalnaya ekonomika [Regional Economy]. Novosibirsk, Izd-vo NGTU, 2012. $196 \mathrm{p}$.

4. Zhukov R.A. Vnedrenie programmnykh ekonomiko-matematicheskikh kompleksov v praktiku deyatelnosti organov gosudarstvennogo upravleniya [Implementation of Economic and Mathematical Software Packages into the Work of State Administration]. Fundamentalnye issledovaniya, 2015, no. 9-3, pp. 555-559.

5. Zhukov R.A. Otsenka sostoyaniya atmosfernogo vozdukha v regionakh TsFO v ramkakh fundamentalnogo podkhoda $\mathrm{k}$ otsenke effektivnosti deyatelnosti subyektov upravleniya sotsio-ekologo- ekonomicheskimi sistemami [Assessment of Condition of Atmospheric Air in the Regions of the Central Federal District in the Framework of the Fundamental Approach to Estimating the Activity of Subjects of Socio-Ecological-Economic Systems Management]. Vestnik Volgogradskogo gosudarstvennogo universiteta. Seriya 3, Ekonomika. Ekologiya [Science Journal of Volgograd State University. Global Economic System], 2016, no. 3 (36), pp. 177-184.

6. Zhukov R.A. Primenenie innovatsionnogo podkhoda $\mathrm{k}$ prognozirovaniyu pokazateley sotsialnoekonomicheskogo razvitiya v MO Uzlovskiy rayon Tulskoy oblasti [Application of Innovative Approach to Forecasting the Indicators of Social and Economic Development in MD Uzlovsky District of the Tula Region]. Vestnik Tulskogo filiala Finuniversiteta, 2014, no. 1, pp. 271-273.

7. Zhukov R.A. Primenenie fundamentalnogo podkhoda $\mathrm{k}$ upravleniyu sotsialno-ekonomicheskim razvitiem territoriy [Applying the Fundamental Approach to Managing Socio-Economic Development of Territories]. Nauchnoe obozrenie, 2014, no. 4, pp. 272-274.

8. Zhulanov E.E. Ekonomiko-matematicheskoe modelirovanie razvitiya vosproizvodstvennogo kontura regionalnoy sotsialno-ekonomicheskoy sistemy [Economic and Mathematical Modeling of the Development of the Reproductive Contour of the Regional Socio-Economic System]. Ekonomicheskiy analiz: teoriya i praktika, 2016, no. 6(453), pp. 172-187.

9. Leontyev V.V. Balans narodnogo khozyaystva SSSR. Metodologicheskiy razbor raboty TsSU [Balance of the National Economy of the USSR. Methodological Analysis of the work of the CSB]. Planovoe khozyaystvo, 1925, no. 12, pp. 254-258.

10. Federalnaya sluzhba gosudarstvennoy statistiki [Federal State Statistics Service]. URL: http:/ /www.gks.ru. (accessed April 20, 2017).

\section{Information About the Author}

Roman A. Zhukov, Candidate of Sciences (Physics and Mathematics), Associate Professor, Department of Management, Tula University, Ryazanskaya St., 1, 300024 Tula, Russian Federation, pluszh@mail.ru.

\section{Информация об авторе}

Роман Александрович Жуков, кандидат физико-математических наук, доцент кафедры менеджмента, Тульский университет (ТИЭИ), ул. Рязанская, 1, 300024 г. Тула, Российская Федерация, pluszh@mail.ru. 